Indian J Anim Health (2021), 60(1) : 98-100

DOI:10.36062/ijah.60.1.2021.98-100

\title{
Cytology based diagnosis of blastomycosis in nasal swab from a canine
}

\author{
A. Gupta ${ }^{1}$, D. Mondal ${ }^{1}$, S. Mondal ${ }^{1 *}$, R. N. Hansda ${ }^{1}$ and S. Pradhan ${ }^{1}$ \\ ${ }^{1}$ Department of Veterinary Pathology, West Bengal University of Animal and Fishery Sciences, \\ Kolkata-700 037, West Bengal, India
}

\begin{abstract}
A male Labrador dog of 7 years old was presented to Veterinary Clinical Complex, West Bengal University of Animal and Fishery Sciences with a history of pyuria, chronic urinary tract infection, decreased appetite, mild nasal secretion with fatigue and occasional cough. Confirmation of fungal infection caused by Blastomyces spp. was done by cytological preparation from the nasal swab. Blastomyces spore was appreciated in the lesion microscopically and the cytological smear also demonstrated the sporulation by the fungus.
\end{abstract}

Key words: Blastomyces, Labrador, Nasal swab

On scientific classification, the genus Blastomyces comes under Ascomycota division, fungi kingdom (Muggia et al., 2020). It has several species i.e. B. dermatitidis, B. emzantsi, B. parvus, B. Percursus, etc. Blastomycosis is a severe and invasive fungal infection caused by several species of dimorphic fungi (Arvanitis et al., 2014). Blastomyces may be found occasionally in humans and other animals in regions where the fungus is endemic. The natural habitat of this fungus is soil, decaying wood, often in an area close to a waterway such as a lake, river or stream.

Among animals, blastomycosis was reported occasionally in dogs but had been recounted in cats particularly in Siamese, horses and in African lion (Schwartz, 2017). The mode of infection is usually via the respiratory tract and the initial lesions are found in the lung. Infection via wound is rare. The disease is characterized by the formation of granulomatous nodules and occurred principally in $\operatorname{dog} s$ and humans. Microscopically, the lesions in dogs consist of a central core of neutrophils and caseous necrosis, surrounded by an intense infiltration of epithelioid cells also containing foci of neutrophils and lymphocytes. Multinucleated giant cells are also present (McBride et al., 2017). There is little tendency towards encapsulation of the lesions. Calcification is rare. Although Hussaini et al. (2018) described that the lesions are usually limited to the lungs, spread of abscess formation may be seen in the spleen, kidney, lymph nodes, liver, brain, bones, adrenal glands etc. Laboratory diagnosis can be done by identifying the spore in the tissue lesion (Miller et al., 2018). The fungal spore is double-walled, thick and typical boot-shaped which is very much characteristics (Yehia and Abdulla, 2011).

A 7 years old male Labrador was presented to the Veterinary Clinical Complex, West Bengal University of Animal and Fishery Sciences, Kolkata with a history of pyuria (pus in the urine), chronic urinary tract infection, decreased appetite and from the last 3 days, it developed a mild nasal secretion. The dog was previously treated with Monurol powder which contains urinary antibiotic fosfomycin, tablet Pan-40 which contain pantoprazole and Uricol powder which contains hexamine, piperazine, khellin and effervescence.

A sterile swab was taken. After soaking with the normal saline solution, it was inserted into the nasal cavity and twisted gently for sample collection. The swab containing the

\footnotetext{
"Corresponding Author
} 
Indian Journal of Animal Health, June, 2021

\section{Cytodiagnosis of blastomycosis in canine}
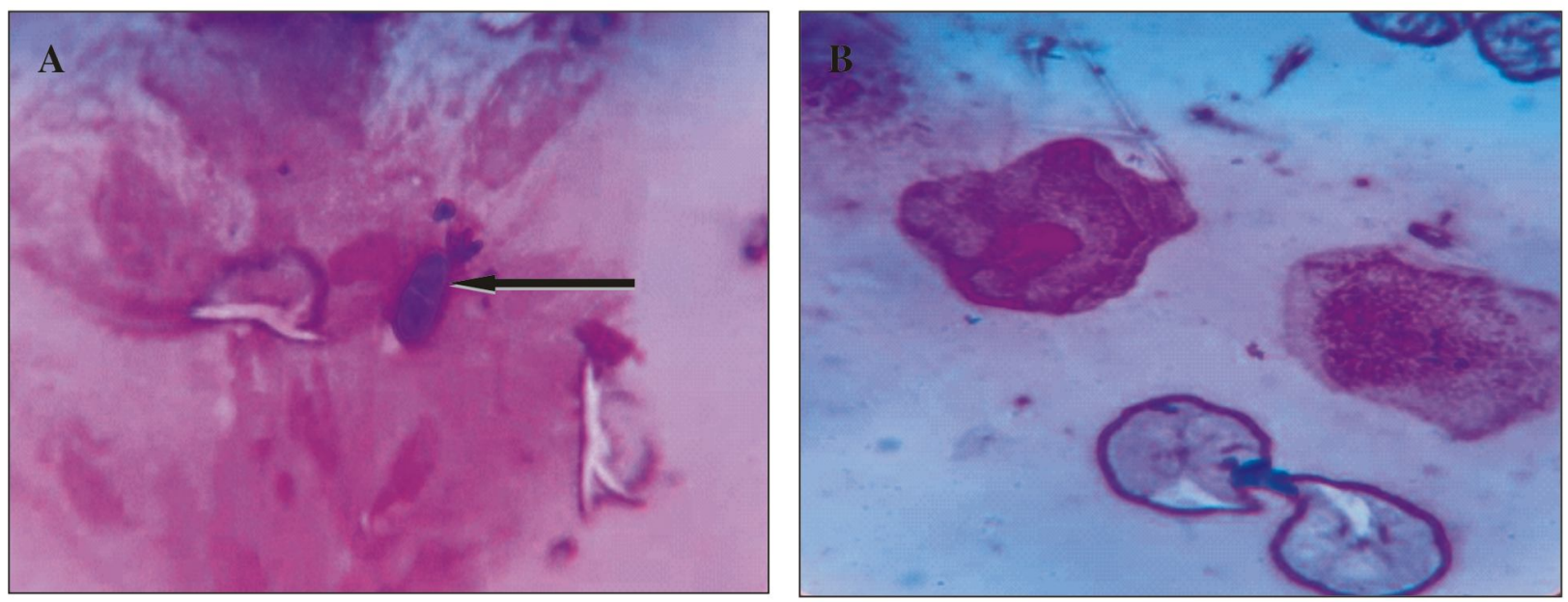

Fig. 1. A. Degenerated epithelial cells and the spore of Blastomyces, B. Showing squamous epithelial cells and mucin, $100 \mathrm{X}$
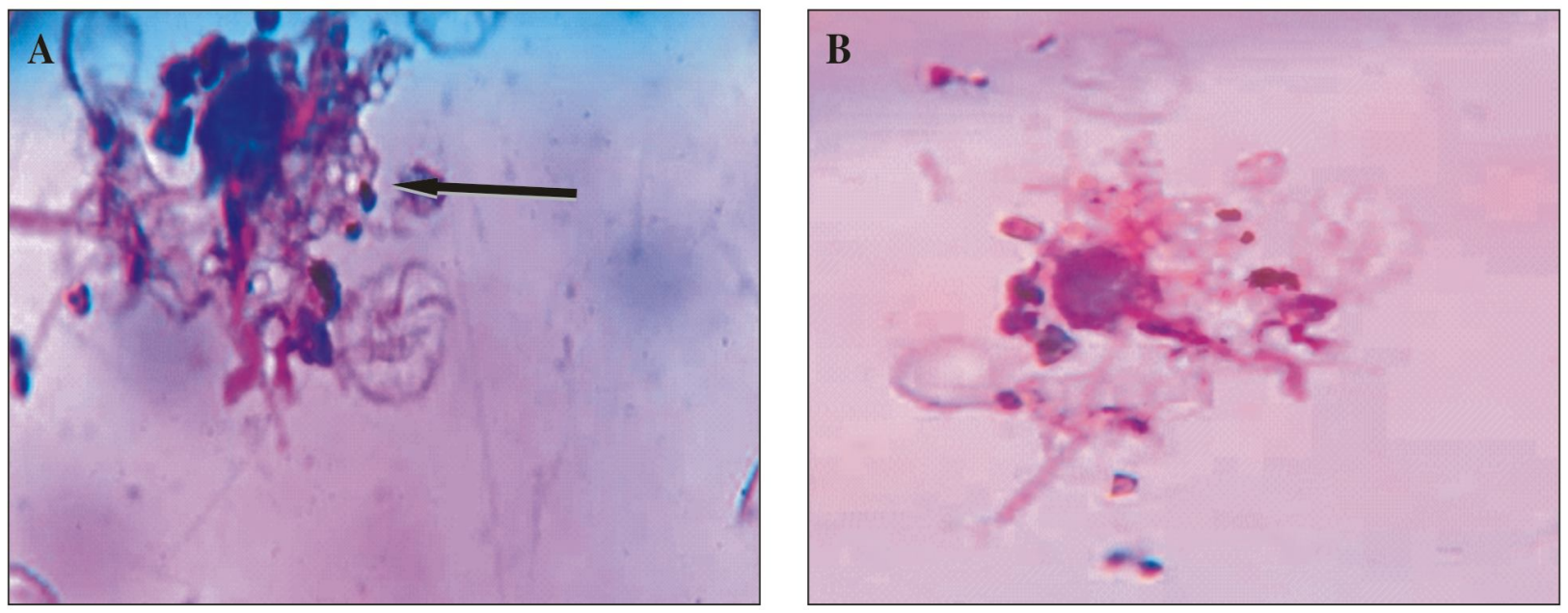

Fig. 2. A \& B. Cytosmear showing photomicrograph of broad base sporulation of Blastomyces, 100X 
sample was then rotated gently on a clean grease-free slide in a unidirectional way for smear preparation. Subsequently, the smear was dried and routine Leishman stain was done. Smear was visualized under the microscope in 100x optical zoom with oil immersion.

Characteristic broad base sporulation was seen in the smear. Also, the lesions depicted double-walled spores which were very much typical for Blastomyces spp. (Fig. 1A). Also, there was the presence of squamous epithelial cells with characteristic angulation, mainly large intermediate type. Smear also exhibited the presence of mucin (Fig. 1B).

The slides showed a large number of sporulating Blastomyces which were ready for disseminating systematically (Fig. 2A and 2B). Based on the above cytological findings, the Blastomyces spp. infection had been inveterated in this case (Miceli et al., 2020). Although it is a rare infection of dogs in India, it might be a sporadic case. History is also correlated with simultaneous distress, fatigue with occasional cough, laboured breathing, and chronic urinary tract infection with the systemic spread of Blastomyces spp. in the urinary system with the clinical manifestation of pyuria (Miller et al., 2018).

In nature, Blastomyces spp. as a fungus forms a mycelium network that penetrates the solid layer on which it grows, and then it begins to reproduce asexually with 2-10 micron conidia (Kohler et al., 2014). These conidia, produced by the fungus are probably the leading infectious agent (Seyedmousavi et al., 2018). They compose on individual short stalks though it becomes airborne when the colony is perturbed. Their size places them well within the respirable size range of particles, meaning

\section{REFERENCES}

Arvanitis M, Anagnostou T, Fuchs BB, Caliendo AM and Mylonakis E, 2014. Molecular and nonmolecular diagnostic methods for invasive fungal infections. Clin Microbiol Rev, 27(3): 490-526, doi: 10.1128/CMR.00091-13 that they can be deposited deep in the lungs when inhaled. Sexual reproduction by the fungus requires the mating of colonies of different mating type and resulted in the production of small ascomata which is nothing but a sexual fruiting body of 200-350 micron size looked like a wooden fuzz ball in the naked eye but in microscopic view, it consists of a layer of spiralling, springy guard hairs surrounding a fertile core in which groups of 8 ascospores (sexual spores) are produced in small round reproductive sacs called asci. The ascospores at 1.5-2 micron are among the smallest reproductive particles produced by fungi and are within the respirable size range.

The budding yeast cells visually perceived in infected tissues as well as in body fluids, are relatively sizable of 8-15 micron and characteristically budded through a broad base or neck, making them highly recognizable (Saccenteand Woods, 2010) as Blastomyces spp. Cytology may be an impetus aid in the field of diagnosis of such cases promptly in clinics.

Conflict of interest: Authors have no conflict of interest in this study.

Contribution of authors: Gupta, A- Collection of the sample, Mondal, D- Processing and preparation of the sample, Mondal, S- Diagnosis and manuscriprt preparartion, Hansda, RNDiagnosis and report generation, Pradhan, SDiagnosis

\section{ACKNOWLEDGEMENT}

Authors are thankful to the ViceChancellor, West Bengal University of Animal and Fishery Sciences, Kolkata for his kind cooperation to perform the work.

Hussaini S, Madut D, Tong BC, Pavlisko EN, Schell WA et al., 2018. Pulmonary blastomycosis presenting as primary lung cancer. BMC Infect Dis, 18(1): 336, doi: 10.1186/s12879-0183244-0 
Kohler JR, Casadevall A and Perfect J, 2014. The spectrum of fungi that infects humans. Cold Spring Harb Perspect Med, 5(1): a019273, doi: 10.1101/cshperspect.a019273

McBride JA, Gauthier GM and Klein BS, 2017. Clinical manifestations and treatment of blastomycosis. Clin Chest Med, 38(3): 435-449, doi: 10.1016/ j.ccm.2017.04.006

Miceli A and Krishnamurthy K, 2020. Blastomycosis. In: StatPearls [Internet]. Treasure Island (FL): StatPearls Publishing; 2021 Jan. Available from: https://www.ncbi.nlm.nih.gov/books/ NBK441987/

Miller JM, Binnicker MJ, Campbell S, Carroll KC, Chapin KC et al., 2018. A guide to utilization of the microbiology laboratory for diagnosis of infectious diseases: 2018 update by the Infectious Diseases Society of America and the American Society for Microbiology. Clin Infect Dis, 67(6): e1-e94, doi: 10.1093/cid/ciy381

Muggia L, Ametrano CG, Sterflinger K and Tesei D, 2020. An overview of genomics, phylogenomics and proteomics approaches in Ascomycota. Life (Basel), 10(12): 356, doi: 10.3390/life 10120356

Saccente M and Woods GL, 2010. Clinical and laboratory update on blastomycosis. Clin Microbiol Rev, 23(2): 367-381, doi: 10.1128/ CMR.00056-09

Schwartz IS, 2017. Blastomycosis in Mammals. In: Seyedmousavi S., de Hoog G., Guillot J., Verweij P. (eds), Emerging and Epizootic Fungal Infections in Animals. Springer, Cham. pp 159-176, doi: 10.1007/978-3-319-720937_8

SeyedmousaviS, Bosco S, de Hoog S, Ebel F, Elad D et al., 2018. Fungal infections in animals: A patchwork of different situations. Med Mycol, 56(suppl 1): 165-187, doi: 10.1093/mmy/ myx 104

Yehia MM and Abdulla ZA, 2011. Isolation of Histoplasma capsulatum and Blastomyces dermatitidis from Iraqi patients with lower respiratory tract infections. J IMA, 43(2): 68-73, doi: $10.5915 / 43-2-5929$

Received - 04.03.2021, Accepted - 02.05.2021, Published-01.06.2021

Section Editor: Prof. S. K. Nandi, Associate Editor 